\title{
CALCULATION OF OPGW STRANDS MELTING DUE TO DC ARC DISCHARGE SIMULATING HIGH-ENERGY LIGHTNING STRIKE
}

\author{
M. Iwata*, T. Nakano, M. Kotari, T. Ohtaka, Y. GodA \\ Central Research Institute of Electric Power Industry (CRIEPI), 2-6-1 Nagasaka, Yokosuka-shi, Kanagawa-ken \\ 240-0196, Japan \\ * m-iwata@criepi.denken.org.jp
}

\begin{abstract}
Metal strands of OPGWs (composite fiber-optic ground wires) installed in overhead power transmission lines are sometimes melted and broken when struck by high-energy lightning. This paper presents the calculation results regarding OPGW strands melting behavior when struck by DC arcs simulating high-energy lightning. The calculations revealed that the melted volume of the strand was $26 \%$ of the strand volume before the arc test, i.e. the rate of the non-melted volume of the strand was $74 \%$. On the other hand, the residual tensile strength of the melted strand was $69 \%$ of the other non-melted strands after DC arc test. These results suggest there is a strong correlation between the calculated non-melted volume of the strand and the measured residual tensile strength of the melted strand.
\end{abstract}

Keywords: ground wire, strand melting, DC arc, lightning, power transmission line.

\section{Introduction}

Ground wires (GWs) have been used to prevent overhead power transmission lines from being struck by lightning. Composite fiber-optic ground wires (OPGWs) have also been used for the aforementioned purpose as well as transmitting high volumes of communication information. Metal strands of OPGWs are sometimes melted and broken when they are struck by high-energy lightning, although the main component of strands is steel. In Japan, winter lightning has high energy and the lightning current can continue for an extraordinarily long time. For example, as shown in Figure 1, the measured current was not a pulse current but similar to a direct current (DC) with a square wave shape [1]. Therefore, in order to clarify the melting and breaking characteristics of conventional and newly-developed OPGW strands, DC arc tests have been performed and the test conditions that adequately simulate high-energy lightning strikes have also been investigated [2-6], and the authors have developed a method of calculating the strands melting due to DC arcs [7].

It is important to clarify the melting and breaking characteristics of OPGW strands with a small cross-section (e.g., $60-80 \mathrm{~mm}^{2}$ ) as thin OPGWs have been melted and broken by lightning strikes on actual transmission lines $[4,8]$. And, it is also important for electric utilities to grasp the residual strength of OPGW which has some melted strands even if the strands are not broken.

In this paper, the calculations regarding the melting (not the breaking) behavior of $60 \mathrm{~mm}^{2}$ OPGW strands when struck by DC arcs were performed, and the calculation results were compared with the test results of the residual tensile strength of the strands after DC arc tests.

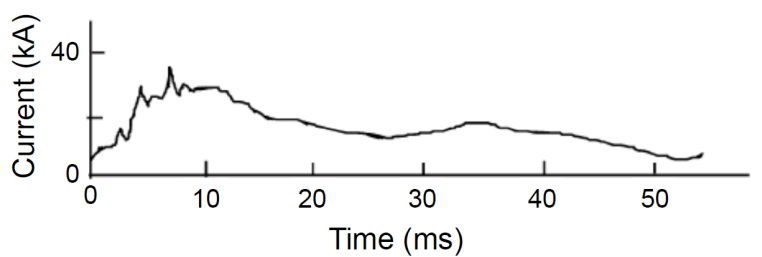

Figure 1. An example of current waveform of winter lightning in Japan [1].

\section{Methods of DC arc test}

In this chapter, the methods and conditions of DC arc tests are summarized.

\subsection{OPGW specifications}

Figure 2 shows the structure of the $60 \mathrm{~mm}^{2}$ OPGW used in the tests. Optical fiber cables were not installed in the OPGW in the tests. The strand type was $23 \mathrm{AC}$, where "AC" denotes aluminum-clad steel, while " 23 " indicates that the electric conductivity of the AC strand is $23 \%$ of that of a copper strand with an equivalent cross-section. The OPGW has six AC strands whose shape is trapezoidal.

\subsection{Test methods and conditions}

Figure 3 shows the setup used for the DC arc tests which were carried out in open air. An OPGW with a length of $5 \mathrm{~m}$ was stretched out at both ends with a tensile force of $12.0 \mathrm{kN}$, which is almost equivalent to the force applied when stringing in actual transmission lines. A thin copper wire with a diameter of $0.2 \mathrm{~mm}$ was stretched between the OPGW and a counter electrode so that the current flowed to vaporize the copper wire and generate an arc. 


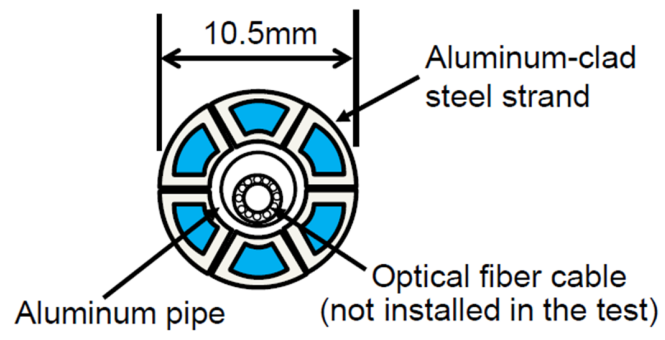

Figure 2. Structure of $60 \mathrm{~mm}^{2}$ OPGW used in the tests.

The counter electrode was an iron rod with a diameter of $20 \mathrm{~mm}$, set above the OPGW with a gap length of $1.5 \mathrm{~m}$ to minimize the influence of the arc jet spouting from the counter electrode on the behavior of an arc near the OPGW. However, the arc root on an OPGW tends to be too mobile to melt the strands because of the electromagnetic force induced by the current flowing through it. Accordingly, conductors were connected to both ends of the OPGW to symmetrically divert the arc current to the earth side so that the arc root was hard to move. In this paper, to investigate the OPGW strands melting behavior fundamentally, an arc was generated only on a part of one strand by winding vinyl tape onto the other part of strands, as shown in Figure 4(a). The length of the exposed (arc-producing) part of one strand was $10 \mathrm{~mm}$.



Figure 3. Setup used for DC arc tests.

The test current was supplied by full-wave rectifying three-phase AC using silicon diodes. The AC was generated using a short-circuit generator $(15 \mathrm{kV}$, 2500 MVA) and a transformer. The DC output can range between $120 \mathrm{kV} / 10 \mathrm{kA}$ and $16 \mathrm{kV} / 60 \mathrm{kA}$ by changing the $\mathrm{AC}$ voltage and the combination of diodes. In this paper, the melting (not breaking) behavior of OPGW strands was investigated fundamentally as described above. Therefore, the test current $I_{\mathrm{DC}}(0.4 \mathrm{kA}(400 \mathrm{~A}))$ and the electric charge $Q$

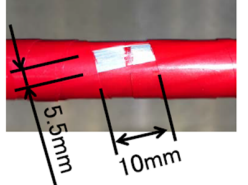

(a)

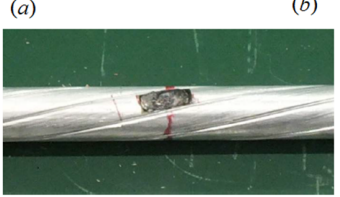

(c)

Figure 4. Photographs (a) before and (b), (c) after $D C$ arc test; in (c) vinyl tape was removed.

\begin{tabular}{cc}
\hline \hline Strand \# & Tensile strength $(\mathrm{kN})$ \\
\hline $1\left({ }^{*}\right)$ & 10.50 \\
2 & 15.05 \\
3 & 15.20 \\
4 & 15.10 \\
5 & 15.20 \\
6 & 15.25 \\
\hline \hline
\end{tabular}

Table 1. Measured residual tensile strength of strands after DC arc test. (*) A part of the strand \#1 was exposed and melted by the arc.

(10 C) were relatively low. The polarity of the current was positive, i.e., the polarity of the OPGW was negative.

\section{Test results}

Figures 4(b), 4(c) show photographs of the OPGW after the arc test. The exposed strand was melted but not broken. It is important for electric utilities to grasp the residual strength of OPGW which has some melted strands even if the strands are not broken. To measure the residual strength of strands, tensile tests of the melted strand and the other non-melted strand were performed individually. Table 1 shows the residual tensile strength of six strands after DC arc test. The tensile strength of the strands \#1, which has a melted part, was $10.50 \mathrm{kN}$. On the other hand, the tensile strength of other non-melted strands \#2-\#6 was $15.05-15.25 \mathrm{kN}$ (average value: $15.16 \mathrm{kN}$ ). These results show the residual tensile strength of the melted strand was about $69 \%$ of those of nonmelted strands. In this chapter, the test results for one specimen (OPGW) were shown. The test results obtained under other conditions for the same kind of specimens showed a tendency similar to the results described above.

\section{Calculation methods and conditions}

Calculations were carried out using the method developed in [7]. This chapter summarizes the calculation methods and conditions. 


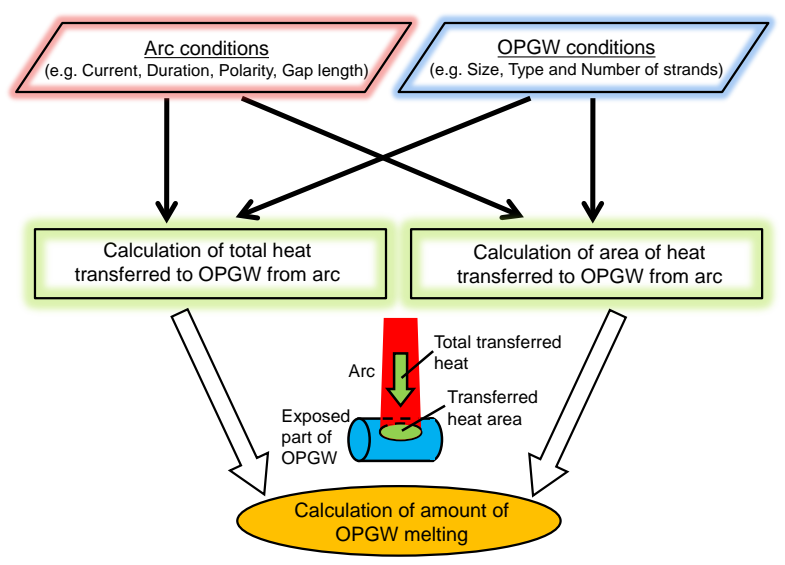

Figure 5. Flowchart of calculations [7].

Figure 5 shows the flowchart used to calculate the melting characteristics of OPGWs due to DC arc. By using the arc conditions (e.g., current, duration, polarity, gap length) and OPGW conditions (e.g., the size, type and number of strands), the quantity of heat and its area transferred to the OPGW from the arc were calculated, and the amount of melting of the OPGW strands due to the arc was calculated. Although the material of the central part of the aluminum-clad steel strand was steel, the material in the calculation was iron since it is the main component of steel and its thermal properties are easily obtained from references.

\subsection{Heat transferred to OPGW from the arc and its area}

The total heat $P_{\text {total }}$ transferred from the DC arc to the OPGW is calculated using the following equation [7]:

$$
P_{\text {total }}=P_{\text {ele }}+P_{\text {conv }}
$$

where $P_{\text {ele }}$ is the heat transferred by electrons emission from the OPGW and by electrons absorption into the OPGW. $P_{\text {conv }}$ is the heat transferred by convection due to the arc jet spouting from the upper counter electrode, where the convective heat from the arc column was not considered because the velocity of the arc column towards the OPGW was thought less than that of the arc jet. For the reference, the heat due to the radiation from the arc to the OPGW, and the joule heating in the OPGW were not considered in this paper, because these heats were thought relatively smaller than $P_{\text {ele }}$ according to the reference [9].

$P_{\text {ele }}$ depends on the polarity of electrode as follows [10]:

In the case of an anode,

$$
P_{\text {ele }}=\left(V_{\mathrm{a}}+V_{\mathrm{w}}+V_{\mathrm{T}}\right) I_{\mathrm{DC}}
$$

In the case of a cathode,

$$
P_{\text {ele }}=\left(V_{\mathrm{c}}-V_{\mathrm{w}}-V_{\mathrm{T}}\right) I_{\mathrm{DC}}
$$

where $V_{\mathrm{a}}$ and $V_{\mathrm{c}}$ are the anode-arc-fall and cathodearc-fall voltages, respectively, $V_{\mathrm{w}}$ is the work function of the electrode. $V_{\mathrm{T}}$ is the voltage estimated by dividing the enthalpy due to the electron drift by the arc current $I_{\mathrm{DC}} \cdot V_{\mathrm{T}}$ is given by the following equation, in which Boltzmann's constant and the value of electronic charge are considered [10]

$$
V_{\mathrm{T}}=\left(1.29 \cdot 10^{-4}\right) T_{\mathrm{arc}}
$$

where $T_{\text {arc }}$ is the arc temperature near the electrode.

These voltages $V_{\mathrm{a}}, V_{\mathrm{c}}, V_{\mathrm{w}}$, and $V_{\mathrm{T}}$ vary depending on the electrode material and the surrounding gas. In this paper, these voltages are the ones for the electrode material aluminum and iron and the surrounding gas air [7], because the OPGW strand was composed of aluminum and iron in the calculations described above, and DC arc tests were performed in the air as described in section 2 .

The convective heat transferred from the arc jets to the OPGW is calculated using

$$
P_{\mathrm{conv}}=h A_{\mathrm{h}}\left(T_{\mathrm{arc}}-T_{\mathrm{OPGW}}\right)
$$

where $h$ is coefficient of the heat transfer and $T_{\mathrm{OPGW}}$ is the temperature of the OPGW surface. $A_{\mathrm{h}}$ is the area of heat transfer, and the estimation method for the area is described below. For the reference, $P_{\text {conv }}$ was less than $1 \%$ of $P_{\text {total }}$ because the spouting velocity of the arc jet was low due to the low current $(0.4 \mathrm{kA})$ and the gap length between the upper counter electrode and the OPGW was long $(1.5 \mathrm{~m})$.

The transferred heat area $A_{\mathrm{h}}$ for $P_{\text {ele }}$ and $P_{\text {conv }}$ was estimated as an area touched by the arc using the following equation assuming that the arc root would stay within the exposed area of the OPGW:

$$
A_{\mathrm{h}}=\operatorname{MIN}\left(I_{\mathrm{DC}} / J_{\mathrm{DC}}, A_{\mathrm{ex}}\right)
$$

where MIN is a function giving the smallest value in the brackets, $J_{\mathrm{DC}}$ is the current density on the OPGW, $A_{\text {ex }}$ is the exposed area of the OPGW. $J_{\mathrm{DC}}$ for aluminum and iron are 60.0 and $33.8 \mathrm{~A} / \mathrm{mm}^{2}$, respectively, and independent of its polarity, which were estimated using the arc current and the arc area evaluated by means of the diameter of the arc root on the electrode measured in [11] assuming that the crosssection shape of the arc root was circular.

\subsection{Simplification of the cross-sectional structure of OPGW strands}

In the case of an actual strand, as shown in Figures 2 and 6(a), the central part is iron (the main component of steel), which is covered with aluminum. In the calculations, the cross-sectional structure of the strand was simplified, as shown in Figure 6(b), to an aluminum layer on an iron layer. The outer diameter $D$ and the cross-sectional areas of the aluminum layer and iron layer in Figure 6(b) are the same as those in Figure 6(a). It was assumed that the heat transferred from the arc was injected into the aluminum layer, which was subsequently melted and removed, whereupon the heat from the arc was injected into the iron layer. 


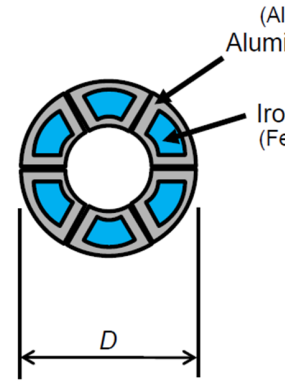

(a) (b)

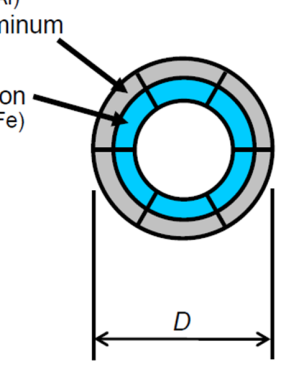

Figure 6. Simplification of cross-sectional structure of OPGW strands ["]. (a) Actual structure, (b) Simplified structure.

\section{Calculation results}

Although the exposed length of strand was $10 \mathrm{~mm}$, the length of melted part of aluminium and steel of the strand was $8.2 \mathrm{~mm}$ and $5.2 \mathrm{~mm}$, respectively, which was measured by X-ray computed tomography (X-ray CT) observation. As shown in Figure 7, the calculated durations required to melt the aluminum layer $(8.2 \mathrm{~mm}$ in length) and the steel layer $(5.2 \mathrm{~mm}$ in length) was $6.3 \mathrm{~ms}$ and $81.9 \mathrm{~ms}$, respectively. The arcing duration in the DC arc test was $27.3 \mathrm{~ms}$. As the aluminum layer was firstly melted and removed in the calculations referring to the observation by X-ray CT, the duration for injecting the heat from the arc to the steel layer was $21.0 \mathrm{~ms}(=27.3 \mathrm{~ms}-6.3 \mathrm{~ms})$. Assuming that the melted volume of the steel part increased in proportion to time, the melted volume of the steel part was $26 \%(=(21.0 \mathrm{~ms} / 81.9 \mathrm{~ms}) * 100 \%)$ of the steel volume before the DC arc test, which means the non-melted volume of the steel part was $74 \%$ in this case. As described in chapter 3, the residual tensile strength of the melted strand was about $69 \%$ of those of non-melted strands. For the reference, a part of the steel of the strand was melted and removed according to the observation by X-ray CT. The lack of a part of the steel would lead to the decrease of the tensile strength of the strand. These results suggest there is a strong correlation between the calculated non-melted volume of the steel part of the strand and the measured residual tensile strength of the melted strand.

\section{Conclusions}

Metal strands of OPGW are sometimes melted and broken when struck by high-energy lightning. It is important for electric utilities to grasp the residual strength of OPGW which has some melted strands even if the strands are not broken. This paper described the calculation results regarding OPGW strands melting behavior when struck by DC arcs simulating high-energy lightning. The calculations were performed considering the heat due to electrons and the convective heat transfer. As a result, the calculation results revealed that the melted volume of the

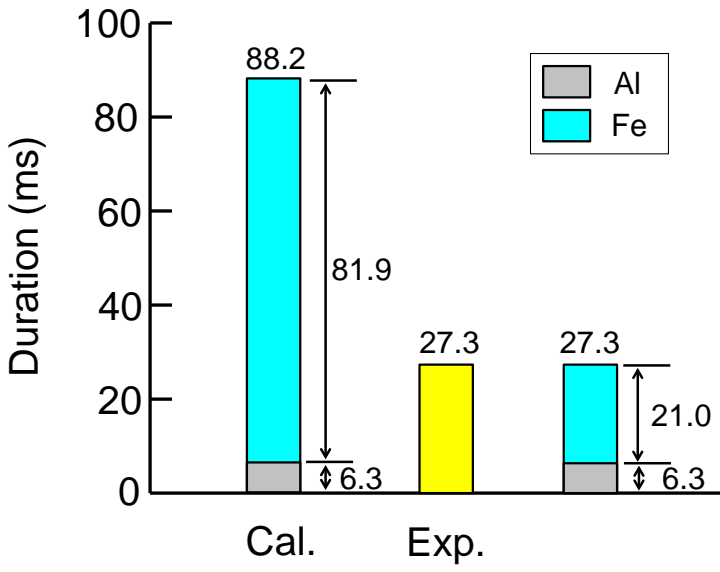

Figure 7. Comparison of the experimental arcing $d u$ ration and the calculated duration required to melt the strand. Cal. - Calculated duration required to melt aluminum and iron layer; Exp. - Arcing duration in test.

steel part of the strand was $26 \%$ of the volume of the steel part before the arc test, i.e. the rate of the nonmelted volume of the steel part was $74 \%$. In addition, the residual tensile strength of the strand after DC arc test was measured. The residual tensile strength of the melted strand was $69 \%$ of the other non-melted strands. These results suggest there is a strong correlation between the calculated non-melted volume of the steel part of the strand and the measured residual tensile strength of the melted strand.

\section{References}

[1] Working Group on Lightning Protection for Transmission Systems. Lightning observation on Japan Sea coast in winter. In CRIEPI Report, chapter T10. CRIEPI, Tokyo, Japan, 1989.

[2] M. Boehme and K. Moeller. Arc motion during lightning test of power ground wires with optical fibers (OPGW). In Proc. 24th Int. Conf. on Lightning Protection, pages 571-575, 1998.

[3] Y. Goda, S. Yokoyama, S. Watanabe, T. Kawano, and S. Kanda. Melting and breaking characteristics of OPGW strands by lightning. IEEE Trans. Power Delivery, 19(4):1734-1739, 2004.

doi:10.1109/TPWRD. 2004.832410.

[4] Y. Goda, M. Shimizu, and A. Matsumoto. DC arc tests of OPGW simulating high energy lightning strike. In Proc. 28th Int. Conf. on Lightning Protection, pages 959-964, 2006.

[5] S.-H. Xie and R.-S. Yang. Study of OPGW performance against lightning strikes in UHV transmission lines. In Proc. 58th Int. Wire and Cable Symp., pages 393-398, 2009.

[6] T. Ohtaka, M. Iwata, Y. Goda, Y. Kuzuma, M. Fujii, A. Matsuba, and K. Nagano. Strand breaking characteristics of OPGW $80 \mathrm{~mm}^{2}$ and AC $150 \mathrm{~mm}^{2}$ by DC arc. In Proc. the 2013 Annual Meeting Record IEEJ, volume 7, pages 150-151, 2013. 
[7] M. Iwata, T. Ohtaka, Y. Kuzuma, and Y. Goda. Development of calculation method for melting characteristics of OPGW strands due to DC arc. In CRIEPI Report, chapter H11003. CRIEPI, Tokyo, Japan, 2011.

[8] J. Huang, X. Chen, and J. Xu. Investigation and analysis of an OPGW lightning strike incident. In Proc. 58th Int. Wire and Cable Symp., pages 389-392, 2009.

[9] M. Shibuya, T. Inaba, and Y. Goda. Molten losses on cut end of rod electrodes in AC high current arc discharge. Inst. Elect. Eng. Jpn. Trans., 113-B:327-334, 1993. doi:10.1541/ieejpes1990.113.4_327.
[10] Y. Kito and T. Mizuno. An experimental approach to melting of aluminium alloy string at an arc spot formed by surging current. Inst. Elect. Eng. Jpn. Trans., 108B:577-584, 1988. doi:10.1541/ieejpes1972.108.577.

[11] Y. Goda, M. Iwata, K. Ikeda, and S. Tanaka. Behaviour of arc jet of $50 \mathrm{kA}$ class high current arc in a long gap. In CRIEPI Report, chapter W00034. CRIEPI, Tokyo, Japan, 2001. 